\title{
Locating the nihilistic culture within Zimdancehall in contemporary Zimbabwe.
}

\author{
Kudzai Mabuto \\ Student of English (BA Hon. English \& Communication Studies) \\ Department of English \& Communication Studies \\ Midlands State University, Zimbabwe \\ kudzaimabuto49@gmail.com \\ $\&$ \\ Umali Saidi \\ Midlands State University, Zimbabwe \\ saeedu2010@gmail.com
}

\begin{abstract}
A fusion of the Caribbean, African American and Zimbabwean music genres into the infamous glocalized Zimdancehall music has dulled the significance of other traditionalist Zimbabwean music genres. Dancehall culture has caused much controversy in Zimbabwean society, being blamed for the country's increase in crime, violence and believed to encourage misogynistic attitudes among Zimbabwean youths through its negative themes. Using appraisal and dramatism theories the article shows the existential crisis the youth in Zimbabwe face due to economic as well as other social forces and thus align themselves to rather destructive misogynistic behaviours which somehow characterises contemporary Zimbabwe. Established in the article is the extent to which language used in Zimdancehal/music is socially charged as well as globalized thus influencing youth feelings, emotions and behaviors. The article analyses lyrics of selected songs as well as makes references to selected musical videos from Zimdancehall artistes such as Soul Jah Love, Winky D, Lady Bee and Killer T as prominent artists revealing what has come to be considered contemporary 'ghetto culture' within popular culture in Zimbabwe. It is further argued that Zimdancehal/has come to shape, inform behaviors, perceptions and aspirations of the Zimbabwean youth largely due to its nature of production as well as dissemination.
\end{abstract}

Key Words: popular culture, ghetto, youth, music, misogynistic 


\section{Introduction}

With the advent of globalization and the need to fit into the global village came glocalisation of Jamaican dancehall music into Zimdancehall. Mashoko (cited in The Standard, 2016) says Zimdancehall is a local music genre heavily influenced by Jamaican Dancehall. The genre appeals mostly to ghetto youths due to their unique circumstances and experiences. On one hand the Jamaican and Zimbabwean experiences differ because of political and social realities of given countries but on the other they are seemingly similar given their resultant conditions of unemployment, access as well as heavy use of technology. Zimdancehall can be traced to Jamaican Reggae music with the likes of Bob Marley, Peter Tosh, Morgan Heritage, Burning Spears, Jimmy London, Luciano, Buju Banton as well as South African artiste like Lucky Dube and many others. As such for the genre that has come to be called Zimdancehall in Zimbabwe, it borrows much from the Jamaican Ragga and Reggae genres. Viriri, Viriri and Chapwanya (2011) view it as part of a larger genre - 'urban grooves' which is a music in which 'local beats are fused with $R \& B$, soul, reggae and hip hop to create a new mode of expression' (Viriri, Viriri \& Chapwanya, 2011, p.84).

One can argue, however, that Zimdancehall has become an independent genre from 'Urban Grooves' although systems of creating new modes of expression may be similar. While Urban Grooves can be attributed to Fortune Mparutsa, Shingai Mau Mau and Prince Tendai Zimdancehall can be attributed to the likes of Major E, Booker Tee, Innocent Utsihwegota and Potato where fusions are made around Reggae and Ragga hence the claim in this article that Zimdancehall is traced to Jamaican Reggae. In some cases, the 'beat' of some songs is directly taken from Jamaican Reggae/Ragga and new lyrics as well as fusions imposed on it.

Whereas acceptance of Urban Grooves is attributed to what Viriri et al (2011) call 'cultural revolution' instigated at a time when Prof Jonathan Moyo became the Minister of Information and Publicity in 2001, for Zimdancehall the same could also be said but the genre in Zimbabwean music gained very little recognition then until new artistes like Winky D, Badman and King Labash came into the scene. More so, a younger generation with the likes of Killer T, Kinah, Shinsoman, Guspy Warrior, Sniper Storm, Freeman, Seh Calaz, Soul Jah Love, Lady Squanda, Empress Shelly, Lady Bee, Tocky Vibes and many others have taken this genre to new heights hence making it appear as an independent but related genre to the urban grooves. The new generation of Zimdancehall artistes have managed to attain a great following especially among the unemployed Zimbabwean ghetto youths from where the music emanates. 
Vahlberg (2010) notes that youths consume more music than any other group in different societies. Technology has powered an explosion of media usage where cellphones -now assumed to be now outnumbering the population in Zimbabwe; iPods, radios, televisions, the internet and computers make music readily available for listeners. For contemporary teenagers and youths, self-discovery hence happens through music. Roberts et al (2003) argue that music is a medium that matters most to adolescents and teaches them various things, does help them sort out their emotions and feelings and does facilitates social interaction. Further, we can submit that music does provide youths with possibilities of venting their day to day frustrations in a constrained socio-economic and political terrain from which it provides them some form of comfort.

It should be noted that a great deal of research, for instance, Viriri et al (2011), Saidi (2015), Manase (2011), Tembo and Mpofu (2015) has been done to reveal the influence, nature and role of music in society which Bennett $(2000, \mathrm{p} .6)$ terms "a motor force" in the cultural construction of the everyday world. Showcased is how musicians, songs and audiences are integrated to the social construction of meanings for their lives which in this case can be investigated by analyzing a musical genre. For Zimdancehall, its form, function and psychological contribution to human behavior, personal growth or lack thereof comes under the microscope in order to judge or explain the paradox which currently exist pertaining to the growth as well as popularity of the genre while it is sometimes considered harmful to society. Thus, music is understood in this article as a text that carries language and expressions which embody artiste's attitude, feelings and emotions which in turn influence behaviors, dreams, aspirations of listeners as well as speak or represent the behaviors, dreams and aspirations of the listeners. If in literary studies, literature reflects society, it follows as well that music has a similar role which can be attributed here.

\section{Conceptualizing Zimdancehall}

Burke (1962) says dramatism theory argues that people's point of view is facilitated through fictitious texts which encompass songs and poetry. In this case, Zimdancehall music and lyrics are a case in point. The dramatism theory thrives on the belief that humanity uses language which truly reflects and represents their reality. According to this theory, there is a link between language and human behavior. It follows, therefore, that to fully understand behavior one has to closely study language in use and its subsequent expressions.

The dramatism theory is characterized by five principles which are; the agent, purpose, scene, act and agency. The agency examines the manner in which the message is communicated. Thus, fully explained by dramatism here is the relationship between language used in Zimdancehall music, artistes and their 
audience. We further recognize that language and thought are ways of human interface. In the case of Zimdancehall, artistes sing about their everyday societal experiences and the experiences of their kin and those that they represent.

To fully conceptualize Zimdancehall, this article also makes reference to the appraisal theory which was developed in the 1990s by Peter White and Jim Martin. According to O' Donnell (2011) the appraisal theory is concerned with the analysis of the way the author or writer views things or people in the text they produce. Hence, the theory is song, artiste and audience cantered vividly showing and explaining the attitudes and the perspectives from which the dancehall artistes are driven in creating their music. Against the appraisal theory we have 'Attitude' which comprises of different ways in which a singer evaluates his/her subjects and environment. In order to understand Zimdancehall one needs to understand the emotions, feelings, position and point of view of Zimdancehall artistes and this can be achieved in part by analyzing their lyrical content of their selected songs.

Further 'Engagement' within the appraisal theory is concerned with how much a singer validates other texts or positions that exist on the same subject. 'Graduation' as a tenet of the theory is concerned with the way attitudes can be adjusted in 'utterances' and in our case in the lyrics themselves. Showcased is the artistic skill and prowess in language use employed by Zimdancehall artistes to relay their messages and reflect upon their conditions. Thus, appraisal theory is useful in the study of messages encoded in Zimdancehall music thereby showing how the dancehall artistes create their music and even allowing to ask, to what end?

\section{Understanding music as culture and a social renegade}

Scott (2007) argues that culture is not fixed as such not static. In other words, culture is fluid, dynamic, a product of history of power struggles; an articulation of agency, of resistance and of dialogue at a given point and time. Therefore, culture is usually defined by those in power with the most agency. In dancehall, we have youth culture which highlights the type of expression and age of the majority of the dancehall participants who are the youths. And so Zimdancehall is characterized by Zimbabwean "ghetto youths" responsible for creating, participating and maintaining this dancehall culture.

Manase (2011) ponders on how Winky D's music is representative of the dynamism and controversy that the Urban Grooves have come to be associated within the cultural performance in Zimbabwe. He analyses Winky D's songs to determine the nature of his music, its sonic aesthetics and significance in expressing the multiplicities characterizing the Zimbabwean situation. Manase argues that Winky D is a significant youth-cultural broker and his performances articulate the social reality 
of Zimbabwean townships such as Mufakose, Mbare, Kambuzuma, Glennora, Chitungwiza, Mabvuku and Tafara to mention a few. Some of the thematic concerns in his music are about dominance of violence, sex and poverty. Manase views Winky D's music as an example of creative synergies that the cultural performance needs so as to meet the standards of the global industry and market.

Viriri et al (2011) also show how popular music influences Zimbabwean youth behaviors paying particular attention to Urban Grooves music lyrics by the likes of Alishas 'Maskiri' Musimbe, the duo Extra Large and Wallace 'Winky D' Chirimuko. Viriri et al (2011) argue that although some of these lyrics appear humorous they have hidden destructive messages. To them, the lyrical content in the selected Urban Grooves songs they study instead of promoting positive cultural values promotes profane speech, fornication, mischief, dishonesty, obstinacy, multiple sex partners and hence to them promote western cultural values (Viriri et al, 2011).

Viriri et al (2011) also discuss how selected artistes view themselves and their worldview of their fellow Zimbabwean youths noting the importance of music in the socialization of the Zimbabwean youth. Viriri et al (2011) brings out the communicative effect in music as investigated and demonstrated in the notion that the Zimbabwean youths tend to interpret musical lyrics literally as they aspire to relive the messages in the songs and concludes that certain artistes should be banned from air play. But what Viriri et al (2011) do not appreciate is the general socio-economic and political conditions the youths exist both as artistes as well as listeners which reflect the creative and deconstruction attitudes of the songs.

Saidi (2015) studied humour in Paul Matavire's selected songs paying particular attention to recurrent themes which are of a social-marital nature such as intimacy, romance and social relations. Saidi applauds 'Doctor Love's' creative nature and traces humour and how through the same social and cultural values, crucial for the maintenance of society are advanced. Brought to light is the communicative yet educative nature of music and the prowess in the use of language and notions of expression not only to entertain but relay messages leaving society picking the bone of social issues. However, this article analyses diction and the communicative aspect of language used in Zimdancehall leading or causing the resultant effects of listening to this particular genre beyond the negative themes exuded in lyrics especially to the youths who are still in their self-discovering stages.

Tembo and Mpofu (2015) observed that one result has been for Zimdancehall to militarize Zimbabwean music itself as evidenced by the use of militaristic expressions in the Zimdancehall music genre. Their analysis brings to light the implications and outcomes of using militaristic images in expressing things that are not militaristic as is the case with Zimdancehall. Artistes like Jah Prayzah, Tally B who calls himself 
the 'Lyrical Lieutenant' Sniper Storm also known as 'The General' and Guspy Warrior to name just a few, Tembo and Mpofu rightly note that they use the name 'musoja' and even their performing regalia, comprises of army combatant uniforms advance this military culture within their songs and stature. However, Tembo and Mpofu (2015) pose that this militarization of life by elevating military prowess in life events has led to the demilitarization of the military service.

\section{Violence, misogyny, drug and substance abuse}

Violence is a recurrent theme in Zimdancehall music and Viriri et al (2011) also did rightly observe. Crawford (2010) argues that there is a correlation between "hardcore" dancehall genre and sexual violent behavior of adolescents and youths as they are likely to respond psychologically to the lyrical contents of the dancehall genre. Also, in support of this notion, Malek (2008) argues that Hip hop music has an influence on violent behavior in American youth and showcased is the downside of the different kinds of music in different societies. The Zimbabwean dancehall situation with Zimdancehall is no different from the Jamaican experience as Zimbabwean youths are fast becoming like the Jamaican Youth. Zimbabwean newspapers have featured a number of articles showcasing the extent to which Zimdancehall is corroding morals and causing unruly behavior among the Zimbabwean youth in both the artistes and their fans.

Mpofu (2014) discusses how violence has become the order of the day as a number of Zimdancehall shows are characterized by violence. Saul Jah Love's engagement party to Bounty Lisa ended up in blows as Seh Calaz and Quonfuzed exchanged blows. This violence is in sighted by rival stables like Gaza and Gully crews in Jamaican dancehall. Zimdancehall also has its own crews like Mabhanditi (convicts), Maninja (ninjas), Dangerzone, The Conquering family to name just a few.

Mbiba (2014) covered a story on how Saul Jah Love and Seh Calaz fought at the Zimdancehall Sting Show in Harare. The fight culminated in spectating fans being tear gassed as police tried to break the fight that had extended from the artistes to their fans and many people were injured in the stampede. The NewsDay (2014) conducted a snap survey and observed that many teenage boys do affirm allegiance to these Zimdancehall crews and have created their own divisions whilst adopting the music themes as part of their lives. Yoz, a Zimdancehall artists, was physically attacked by unknown assailants as he left the Zimdancehall awards. When asked for his comment by The Newsday he recognized them as 'Seh Calaz's thugs' (The NewsDay, 2014). This shows the amount of violence in Zimdancehall as the artistes fight against themselves resulting in fans of either artiste pitted against each other in a fight that is no longer lyrical but physical. 
The NewsDay in its snap survey in 2014 further observed that bars no longer consider the legal age restriction. Twelve-year-old girls were reported to have been seen in bars, young boys seen playing pool, puffing cigarettes and students have been notably seen in bars in their school uniforms. Marufu (2014) laments how the Body slam riddim launch was characterized by spectators of all age groups even those of school going age. Further, The NewsDay (2014) established that Boncleer and Histalix D are commonly used drugs by some of the Chitungwiza youths and they sell for $\$ 3$ or $\$ 4$ in Chitungwiza streets. Ironically, some Zimdancehall artistes are known abusers of cough mixtures and Marijuana. The likes of Soul Jah Love, Killer T, Guspy Warrior, Winky D, Empress Shelly, Platinum Prince and King Shady just to name a few were cited as examples (The NewsDay, 2014).

Naidoo and Pfukwa (2009) examined the images of women in contemporary Zimbabwean music and lament how the Zimbabwean woman has been commercialized at the expense of intellect. The ideal Zimdancehall woman is one with a full curvy figure, beautiful face, light skin, form fitting clothing and wears sexy lingerie. In short, she is all about the sex appeal and should know how to 'party'. The study further discusses what informs these Zimdancehall perceptions on women and how it affects the wider society. Naidoo and Pfukwa (2009) applauds the move by musicians to hail the Zimbabwean woman of African beauty but contests that Zimbabwean musicians should empower women by bringing out their best beyond women's domesticity as mothers, wives and care givers.

As such Zimdancehall is not spared the guilt of propagating sex and prostitution where glorification of sex and exhibition of women as sex objects has continued to become a prevalent theme in Zimdancehall music as is illustrated below;

\section{Platinum Prince featuring Zoey, Mona Wakandigarira}

Mona wakandigarira, (gyrate while sitting on me)

Wakandigarira bhebhi ndozvifarira.

(While sitting on me, babe I like that)

Chingobhenda kunge banana-na-na-na, womazunza zveminana-na-na-na

(Just bend like a banana, and shake them amusingly)

Bhawa rese ndiwe wandakhuza, ndiwe urikugona kumazunza

(You are the best dancer in this bar, and the only one shacking amusingly your butt)

Saka dzikirira wokwirira, ini kumasure ndonamirira

(So, slowly go down and gently rise, while I get stuck on your back)

Totamba kusvika tadikitira, kuita serious uchindiwayinira...

(We will dance until both of us sweat, being serious while you gyrate for me) 


\section{Ricky Fire featuring Bev, Ndiratidze Zvaunoita}

Kanauchiti unotamba bhebhi ndiratidze zvaunoita

(If you say you can dance, Babe show me what you can do)

Kana uchiti unogona kuwayina bhebhi ndiratidze zvaunoyita

(If you say you can dance, babe show me what you can do)

Kana uchigona kutambisa riri one, ndiratidze zvaunoyita

(If you can jiggle one buttock, show me what you can do)

Platinum Prince in his song Mona Wakandigarira gives a vivid description of a woman dancing with him on the dance floor as she presses her buttocks against his groin and gyrates against him while she is bent down like a banana. He applauds her on how he enjoys the way she moves. These are the sentiments Viriri et al (2011) detest and the same songs as consumed on video reflect the images of sex and sexual engagement as though complimenting the lyrics captured in the song.

Showcased in the musical videos are near naked women, raunchy and sexually suggestive dances. Hence, Zimdancehall has faced great distaste from parents and the older community who curse lewd lyrical content and the glorification of youth-sex. Marufu (2014) posits that teenage girls in Zimdancehall fall victim as bait as they are targeted by older man in bars and society in general thereby revealing the undeniable negative impact of Zimdancehall to the younger generation.

Kistler and Lee (2009) assert that sexual musical videos are associated with beliefs about women as sex objects as well as sexual permissiveness and stereotypical gender attitudes. Indeed, against this, Zimdancehall is a cause for concern as adolescents might be particularly susceptible to the influence of sexual music videos on their stereotypical sexual beliefs. Kistler and Lee (2009) motion that the result of these videos are sexually aggressive beliefs. Ricky Fire's song Ndiratidze zvaunoita (show me what you can do) and Platinum Prince's song Mona wakandigarira (gyrate on my lap) feature women in provocative clothing doing raunchy dances as they shake their buttocks gyrating or 'tweaking' as is popularly known in dancehall culture. Another instance of the above style is Soul Jah Love who sings;

\section{Soul Jah Love, Ndongosimudza musoro (I raise my head)}

\section{Ndongosimudza musoro kunge guти kuти}

(I just lift my head like a lizard)

Ndikakushaya bhebhi ndoita chi dhamu, dhamu

(Without you babe I become down syndrome)

Ndobva ndati bhebhi tanga nekubathroom tozopedzerana kanatapinda mubedroom (I then say Babe start by going to the bathroom and then we square off each other in the bedroom) 
Ndobva ndati karika top ehe, bvisa, nyangwe kari kashort ehe bvisa (Then I say, undress, even if it is a short, yes, undress) Bvisa iwe usada kundimisa iwe, wabvira kudhara iwe (Undress do not keep me waiting, you have been stalling) Uchida kundityisa, asi nhasi ndokurwisa iwe, bhebhi (Trying to scare me but today I will wrestle you, babe) Inini newe itori personaly, ndokubata bho, professionally (Me and you it's a personal affair, I always treat you good, professionally) Ndichikavirira paunowayinira uchidzikirira uchi ah (I will be working while you whining downwards)

Arikuita kunge arikutamba achifamba, achifamba achitamba nebody language (It is like she is dancing, while she is walking with her body language)

Ane body language, andipa appetite, kuita kunge kasandwich ndambobikirwa kasoseji

(She has body language, she has given me an appetite, like a sandwich, a sausage has been cooked for me)

The above lyrics by Soul Jah Love in the song Ndongosimudza musoro (I raise my head) show the extent to which man lust for women and how they celebrate sex. Described by Soul Jah Love is his encounter with a beautiful woman he exchanges paths with along the corridor and immediately lusts for her. He then describes what he imagines he will do to her as he undresses her as they have sex. The video gives a clear picture of the notion of sexual glorification as it also features semi naked in suggestive sexual aura. This is what Chari (2009) laments, mostly how this genre of music is corroding local cultural values where the language carrying the lyrics and the images created are more western in their expressive values.

Sexual intercourse is now the main event in every Zimdancehall chant as clearly demonstrated above. It is not heard of in Zimbabwean culture for one to talk about sexual intercourse in public as it is a sacred private act that happens behind closed doors and reserved for the mature married members of the society. According to Becker (2001) lyrics in Soul Jah Love's song above are sexually suggestive and create unsettling emotions of shame, lust and disgust as they are a deviation from the cultural norms of the Zimbabwean society where people view sexual intercourse as a private and sacred matter.

\section{Masculinities and misogyny in Zimdancehall}

In Zimdancehall music women are presented as inferior to men. Dramatism and appraisal theory aid in showing us exactly what influences these Zimdancehall artistes to portray women negatively. The socio-economic forces where there is a high rate of unemployment has forced some women to engage in sex work and exotic 
dancing in night clubs and taverns to earn a living. An example is provided by Bev Sibanda who has now become 'a household name' for exotic dancing. As such, the music appears to compliment these actions or influence such behaviors as their respective lyrics do fit with Zimdancehall. Gender relations like hegemonic masculinities that are prescribed by societal norms, values and the traditional Zimbabwean culture easily find expression and promotion through this type of music.

More so, local township ghetto conditions like shebeens and taverns where some ghetto women are shebeen queens give men the perception that women are worthless and deserve no respect. These conditions inform the perceptions of Zimdancehall artistes towards women leading to further negative degrading perceptions of women and their resultant treatment. Hence, the scourge of rape, abuse and even child marriages in the country may be attributes to these.

Burke (1962) says in dramatism, language is a form of symbolic action, meaning, words in a text such as lyrics serve to define, appease, divide, entertain, move, victimize, identify or persuade. In the case of Zimdancehall misogyny is showcased through lyrics that encourage, condone or glorify objectification, exploitation or victimization of women. However, misogynistic messages seem less in Zimdancehall unlike in Jamaican dancehall. In this study, however, it is a matter of significance but the nature and intensity of the misogynistic messages in the lyrics rather than the frequency. By describing the woman as an erotic dancer and merely a machine for the gratification of men as well as for use by men to fight their own bar-wars, Zimdancehall artists succeed in creating a culture of unmeasurable dominance. Hence Guspy Warrior, Ricky Fire, Soul Jah Love and Platinum Prince represent through their lyrics, typical men in Zimdancehall culture as well as expose the attitude of man towards women in contemporary Zimbabwe. Showcased is how women in dancehall do degrading things and submit to misogyny for the approval and enjoyment of men as the bedroom experience is recreated on the dance floor.

Connell and Masserschmidt (2005) assert that the current most honored way of being a man requires all other man to position themselves in relation to the ideological, global subordination of women by men. This masculinity or for one to be recognized as a man in global $21^{\text {st }}$ century music society, men 'are required' to have attitudes that objectify women and practices that subordinate them. In Zimdancehall this ideal man is achieved by linguistically objectifying women which is further reflected by the music videos that advance and propagate submissive roles, untrustworthy, promiscuous prostitutes, money mongers and party animals. The following song, Seunononga exude the level of misogyny in Zimdancehall music by most male artistes: 


\section{Guspy Warrior, Seunononga}

Ita seunononga, mi gyal, bata pachest apa uchiwayina

(Act like you are picking up something my girl, hold my chest and gyrate)

Runako nemalips ako aripink baby girl, nema curvy hips

(Your beauty, pink lips and curvy hips)

Mafia rese ribilivhe kuti ndini ndakaskupa heavy simbi.

(Convince all my friends that I have the hottest girl)

Bata pasi uchiita sewakandigarira, kune ka new dance kanonzi kaseunononga.

(Touch the floor as if you siting on me, there is a new dance)

Called Like-you-are-picking-something)

Ita seune chawa dropa ukutraya kuchinhonga girl, apa uchitondiwayinira.

(Act like there's something you have dropped and you're trying to pick it up while gyrating for me)

Ndiwayinire, ndiwayinire uya padhuze neni bhebhi usavhunduke

(Gyrate for me, gyrate for me, come close to me babe do not be scared)

Wayina ndipe zvese usasiirire ndoda $x$-girlfriend yangu igumbuke...."

(Gyrate give me your all do not leave out any detail, I want to make my x-girlfriend jealous)

Inonzi seunononga kanakuti fongo, asi ndeyevanhu two chete kwete povho ...

Guspy Warrior in this song describes his woman on the dance floor. Described is her beauty, dimples, pink lips and curvy hips with no brains. Naidoo and Pfukwa (2009) argue, is an instance of the commercialization of women's physical body and beauty above intellect. Hence, Naidoo and Pfukwa (2009) are right to protest and call for the Zimbabwean women to be viewed and treated beyond their looks and their stereotypical position in society. In the song, the girl has to 'twerk', gyrate or bounce her buttocks in the manner of a new dance being described by the artist so he can boast to his mates and show off to his ex-girlfriend as the 'real man' with the hottest girl on the dance floor.

Ironically, women Zimdancehall artists also complement their male counterparts and we do not have a single artist who counters or questions these male positions as demonstrated by Lady Bee in her song Bamudiki whose extract lyrics are reproduced below;

\section{Lady Bee, Bamudiki vari Fiti}

Bamunini vari fit, vari sexually revealing

(My husband's young brother is fit and sexually revealing)

Ende vari appetizing, miyedzo yandikunda mhani

(And he is very 'appetizing', I have given in to temptation)

Yohwee Bamunini ndaminyuka, nditakureyi munondiiisa mumba 
(Ouch! My husband's young brother, I have sprained my ankle will you carry me inside the house)

Pamubhedha mubedroom vondiisa

(He puts me on the bed in the bedroom)

Monyatso nhanzira, nechepa ibvi Bamunini kwizai

(Rub me on my knee, don't hesitate rub properly)

Nechepamusoro ehe kwidzai, muchipuruzira, muchifuridzira

(A little further at the top kip, yes please rub)

Neche papa apa.

(Right there)

Lady Bee's song Bamudiki vari fiti portrays the Zimdancehall woman as a lustful, promiscuous being. What might be a case of sexual independence and emancipation of the Zimbabwean woman labels her the temptress. To her, sex is just but an act and there is no morality to it as she tries by all means to sleep with her husband's young brother. This is taken further in her song Vavengi in which she reacts to society by asking why it is concerned about her so called 'immoral' behavior or her sexual engagements asking 'zvine basa rei?' (Of what value is it to you?). These are the very same attitudes these artists exude for their followers to imitate, adolescent girls and ghetto youths eventually copy their acts, dressing and the lifestyles they portray in their videos.

Another recurrent theme in Zimdancehall is that of parties as people spend and drink to the extent of forgetting their morals. Jamaican dancehall features Pasa Pasa parties that are characterized by semi naked women drugs and alcohol. Zimbabwean dancehall is imitating Jamaican dancehall as there has been a series of open space parties. The following Zimdancehall songs vividly describe what happens in bars and these Zimdancehall parties:

\section{Shinso man featuring Yoz, Tasangana Zvidhakwa}

Togona kutora Breakers tomiksa neSkippers, titambidzei Viceroy tonyika muviniger (We can take Breakers and mix it with Skippers, hand us Viceroy let us mix it with vinegar)

Kokutyei Tasangana zvidhakwa, tadhakwa, todhakwa kunge tisati tambodhakwa

(We are not afraid, when drunkards meet, we drink and get drunk like we have never been drunk before)

Tasangana zvidhakwa hamusati mationa isu takadhakwa

Ndadhakwa ini ndirikunzwa kuda kungoramba ndichidhakwa

(I'm drunk but I feel like getting drunk some more)

Tadhakwa, hatisikuda kubatwa, tadhakwa toita kunge Tom and Jerry 
Locating the nihilistic culture within Zimdancehall in contemporary Zimbabwe.

(When we are drunk we don't want to be restrained, when we are drunk we act like Tom and Jerry)

PTK udza DJ apule riddim nzenza dzitiwayinire

(PTK tell the DJ to pull the riddim so girls can gyrate for us)

\section{Shinsoman featuring Yoz, Marambadoro}

Zvirinani kurasa hunhu panekurasa doro,

(It is better to throw away morals than to throw away alcohol)

Kana kurasa munhu panekurasa doro

(Or losing a person than alcohol)

Tozviitira chifinhu ndinemarambadoro

(We just do it for the fun of it, we have bad behavior when we are drunk)

Ndokutura nepurezha ndokupinza muforo

Tora mari yako bheja, bheja, bheja, bheja

(Bet all your money, bet it all)

\section{Winky D, Awuya wuya}

Nhasi ipurezha naBiggie kana kumba handiindi

(Today its pleasure with Biggie, I am not going home)

Ndotsvakisa vanhu purezha kunge basa

(I make people look for pleasure like employment)

Kufara kusvika vanhu vati tasa, purezha mahara kunge Pasa pasa

(Happiness until people surrender, pleasure is free like Pasa Pasa)

Zvimoko zvotambisa muchiuno kwasa kwasa

(Girls shaking their waists, kwasa kwasa)

Inguva yekufara iwe mirayi kusasa

(It is time to be happy stop complaining)

Munhu wochema, munhu watirasa, hunhu titahutora kana purezha yagasa

(People are crying, we will take back our morals when the pleasure is over)

Danzi rava papeak, vanhu vakufara semapurisa akandwa kutraffic

(The dance floor is at its climax, people are happy like traffic police)

Winky D chants about how he makes people party hard and look for parties like employment. Instead of singing about good values and solutions to socio- economic problems faced by the youths like employment and the HIV and AIDS pandemic. He encourages youths to forget their morals and party as he sings 'hunhu tichahutora kana purezha ragasa' (we will reclaim our morals when the party is over). Shinsoman and Yoz chant that it is better for one to throw away their morals and family than throw away alcohol. Alcohol is given so much importance such that it 
comes above all else even family relations. Zimdancehall is encouraging alcohol consumption even for under age adolescents as drinking is given such high regard.

The perceptions of these artistes on the audience and society they live in is quite perplexing. They see no hope for their fellow ghetto youth and instead of teaching good values and showing exemplary behavior Shinsoman and Yoz in their 'Tasangana zvidhakwa' (We the drunkards have met) video are too drunk to even walk on their feet but rather are pushed in a cart. They encourage extravagant spending of money in bars and gambling when they sing 'mari yako bheja, bheja, bheja, bheja' (spend your money bet it all). Shown is the extent to which Zimdancehall has no regard for individual growth and molding a responsible generation but rather drunks and gamblers.

Burke (1962) views life as a dramatic act driven by motives and how profound thoughts are expressed through fictional texts like poetry and music. Zimdancehall music becomes a text that describes the Zimbabwean society in all its aspects. The 'Act' aspect shows how Zimdancehall artistes engage in criminal activities like drug abuse, bribing police officers if caught on the wrong side of the law, corroding the moral values of society with the immorality they chant in their music and videos. The 'Scene' aspect of dramatism portrays how Zimdancehall artists view the Zimbabwean society as one that associates success with fame and crime rather than proper channels of working hard and educational attainment. The dramatism "Purpose" proves Zimdancehall as an agent of moral and cultural corrosion. Therefore, Zimdancehall to a greater extent is not concerned about the message it relays to its listeners but rather some artistes just sing for fame, money and recognition be it for singing garbage lyrics or tearing away from the moral fabric of the Zimbabwean society.

\section{Locating existentialism in Zimdancehall}

The above is a detailed presentation of instances that to a greater extent agree with Viriri et al (2011), Chari (2009) and others who have tried to demonstrate how the genre under discussion is a genre of moral and cultural decay. However, we need to note that apart from the listeners or music consumers being influenced by the music, we may also submit that the artists, apart from a great number of them being reported as actors of their lyrical messages, much of their messages and use of language may be seen as a true reflection of what the youth are in the country. If literary or fiction writers can be viewed as able to creatively reflect the nature of their communities, it follows that Zimdancehall artists are also reflecting on what their society has created. They have been battered by the poverty of the ghetto as well as subjected to the wrath of hunger, betrayal and psychological pain. One sees youths unable to make sense of their situations hence unable to save themselves from the very unbecoming situations 
they find themselves in. As such the use of language and the continued productions of songs that continue to build up on these themes go a long way in showing the sorry state the youth find themselves in especially in contemporary Zimbabwe.

This hence reflects the existential problem youths in Zimbabwe face which has become a condition catapulted by a number of factors. Unemployment can be thought to be the first culprit with over $80 \%$ unemployment rate in the country it follows that youths find themselves in a quandary in which they either do not stay in school or are unable to enroll in colleges as their parents have no monies for their tuition. The dilemma youths face can be further aligned to the culture of materialism propagated through the new media systems where technology has made it easier for youths to access global and local content fast. What we note is thus a development of a youth culture to which forms of music such as Zimdancehall speak directly and reflect this culture as a plea to society in general to change the socio-economic and political conditions of the youths rather than have the music change the same. The music can merely advocate and reflect what may characterize their society and being.

\section{Conclusion}

The article has shown Zimdancehall's socio cultural relevance to contemporary Zimbabwean society. Despite creating employment, the genre's creativity mirrors the Zimbabwean society although the resultant behaviors are read as a corrosive force to be reckoned with as its ill morals are fast permeating through society's moral and value system. One's understanding of Zimdancehall music should thrive beyond the mode by which Zimbabwean youth express themselves. To understand Zimdancehall as a culture and a social renegade one needs to credit the Zimdancehall artists as cultural brokers who in fact reflect the music and culture in general as a negotiated as well as contested space. The artist's significant role at the pinnacle of culture must be understood as they use their lyrical talent to bring about cultural change to society be it in a negative or positive way. The Zimdancehall artist can thus be seen as a social misfit engulfed in identity crisis and suffering from existential problems given the unwelcoming socio-economic terrain they find themselves. It is hoped that what Zimdancehall reflects be read with the socio-economic as well as technological situation in mind in order for society in general especially through the involvement as well as participation of the older generation; and other stakeholders active involvement to promote the betterment of their socio-economic conditions for cultural benefits. 


\section{REFERENCES}

Becker, J. 2001. Anthropological perspectives on music and emotion. In: Music and emotion: Theory and research, eds. Juslin P. N. \& Sloboda, J. A. pp.135 - 60. Oxford: Oxford University Press.

Bennet, A. 2000. Popular Music and Youth Culture: Music, Identity and place. Basingstoke: Macmillan.

Bennet, A. 2005. Culture and Everyday Life. London: London Sage.

Blakesley, D. 2002. The Elements of Dramatism. New York: London.

Burke, K. 1962. A Grammar of Motives and a Rhetoric of Motives. New York: The World Publishing Company.

Chari, T. 2009. Continuity and change: Impact of global popular culture on urban grooves music in Zimbabwe, Muziki: Journal of Music Research in Africa 6(2):170-191.

Connell, R. W. \& Masserschmidt, J. 2005. Hegemonic masculinity: Rethinking the concept. Gender and Society. 19: 128- 59.

Crawford, A. D. 2010. The effects of dancehall genre on adolescent sexual and violent behavior in Jamaica: A public health concern. North American Journal of Medical Sciences, 2(3):143-145.

Kistler, M. E. \& Lee, M. J. 2009. Doe's exposure to sexual hip- hop music videos influence the sexual attitudes of college students? Mass communication and society, 13: $67-86$.

Malek, A. 2008. Violence in Language: Is Rap Music Causing Violence in America?, in Violence, Realities and Concerns. Beirut: Notre Dame University Press.

Manase, I. 2011. The aesthetics of Winky D's Zimbabwe urban grooves music and an overview of his social commentary on the post-2000 experiences in Harare and other urban centres. Muziki: Journal of Music Research in Africa 8(2):81-95.

Marufu, V. 2014. Zimdancehall's impact on younger generations. The NewsDay 13 November 2014.

Mbiba, L. 2014. Police in Zimdancehall warning. The Daily News19 May 2014.

Mpofu, M. 2014. NACZ takes action on Zimdancehall violence. The Chronicle 14 November 2014. 
Locating the nihilistic culture within Zimdancehall in contemporary Zimbabwe.

Mpofu, P. and Tembo, C. 2015. Militarising music and demilitarising the military: making sense of "musoja" in Zimdancehall music. Muziki: Journal of Music Research in Africa 12(1):103 -121.

Naidoo, S. and Pfukwa, C. 2009 Representations of women in Zimbabwean contemporary music, Muziki: Journal of Music Research in Africa 6(2): 145-153.

O’Donnell. M. 2011. Language, Function, Cognition. Week 6: Appraisal: The Speaker's evaluation of things in the text.

Roberts, D. F., Christenson P. G and Gentile, D. A. 2003. The Effects of Violent music on Children and Adolescents. Media Violence and children, pp.153-170.

Saidi, U. 2015. Tracing humour Paul Matavire's selected songs. Muziki: Journal of Music Research in Africal2 (1): 53-61.

Saunyama, J. 2016. Zimdancehall remains in the hole. The Standard. 03 January 2016.

Scott, J. W. 2007. The Politics of the veil. Princeton, N J, Princeton University Press.

Vahlberg, V. 2010. A survey of three studies about youth media usage. Newspaper Association of American Foundation.

Viriri, A., Viriri, A. \& Chapwanya, C. 2011. The influence of popular music, in particular urban grooves lyrics on the Zimbabwean youth: The case of Troika Maskiri, Winky D \& Extra Large. Muziki: Journal of Music Research in Africa 8(1):8295.

\section{Discography}

Guspy Warrior 2013. Seunononga, Punch line music. Rebel World Records.

Lady Bee, 2014. Bamudiki vari fiti, Murume. Mockery Production Videos.

Platinum Prince featuring Zoey, (2014) Mona Wakandigarira. Sky Rocket Films.

Ricky Fire featuring Bev, 2015. Ndiratidze Zvaunoita, Madlevels Riddim. Chill Spot Records and Jeepers Legendary Music.

Shinsoman and Yoz 2014. Tasangana Zvidhakwa, Body Slam Riddim. Dr Clarence Video, PTK Body Slam Records.

Shinsoman 2014. Marambadoro. PTK Body Slam Records. 
Kudzai Mabuto and Umali Saidi

Soul Jah Love 2014. Ndongosimudza musoro (Clean version), Zimbo flavor riddim. PTK Body Slam Records.

Winky D, 2014. Awuya wuya, Mudhara Vauya. Gafa life Kickstape. 